\title{
Identification of ,natural“" breaker cut during the machining of carbon steels
}

Karol Vasilko, Faculty of Production Technology, TU in Kosice with seat in Presov, Bayerova 1, Presov. Slovak Republic.

Tool wear is generally considered a negative fact, which worsens machining results. According to theories it causes the growth of cutting forces, cutting temperature worsens the quality of machined surface. Closer study of the process of the wear leads to the need to distinguish between the effects of the wear on the back and on the face of the tool. The paper deals with the study of the mechanism of wear on the face in time relation. It shows that the groove on the face, which is created by leaving chip, can have positive aspect. It can be used as „natural chip shaper“6.

Keywords: cutting tool, tool wear, machining time, tool life

\section{References}

[1] BOBROV, V, F, et al.: Razvitije nauki o rezanii metallov. Moskva: Mašinostrojenije, 1967, $414 \mathrm{~s}$.

[2] BUDA, J., VASILKO, K.: Nová metóda na zastavenie procesu obrábania bez špeciálnych prípravkov. Patent SR č. 122243

[3] GRANOVSKIJ, G, L., GRANOVSKIJ, V, G.: Rezanije metallov. Moskva: Vyššaja škola, $1985 \mathrm{~m} 304$ s.

[4] GAZDA, J.: Teorie obrábění. Průvodce tvorbou třísky. Liberec: TU, 2004, 112 s., ISBN 80-7083-789-6

[5] GRZESIK, W.: Podstawy skrawania materialow metalowych. Warszawa: Wydavnictwa Naukowo-Techniczne, 1998, 380 s., ISBN 83-204-2311-2

[6] HOSHI, K., HOSHI, T.: On the metal cutting mechanism with the built-up edge. Mem. Fac. Engng, Hekkaide University 12 , с̌. 3,1969

[7] KALPAKIJAN, S.: Manifacturing engineering and technology. New York: Eddison Wesley Publishing Company, 1989, 1999 p., ISBN 0-201-121849-7

[8] KOVAČ, P., MILIČIČ, D.: Rezanje metala. Novi Sad: Univerzitet u Novom Sadu, 240 s., ISBN 86-899-0015-1

[9] LOLADZE, T, N.: Stružkoobrazovanije pri rezanii metallov. Moskva: Mašgiz, 1952

[10] MÁDL, J., KVASNIČKA, J.: Optimalizace obráběcího procesu. Praha: Vydavatelství ČVUT, 1998,168 s.

[11] PŘIKRYL, Z., MUSÍLKOVÁ, R.: Teorie obrábění. Praha: SNTL, 1982, 235 s.

[12] SIMONEAU, E., ELBESTAWI, M, A: The Effect of Microstructure on Cháp Formation and Surface Defect in Microscale, Mesoscale, and Macroscale Cutting of Steel. Annals of the CIRP, Vol. 55/1/2008

[13] TRENDT, E, M.: Metal Cutting. London - Boston: Ed. Oxford, Butterworths - Helnemann, 1991, 273 s., ISBN 07506-1068-9

[14] WRIGHT, P, K.: Applications of the Experimental Methods Used to Determine Temperature Gradients. In: Cutting Tools. Austrial Conference Manufacturing Engineering. Adelaide, 1977, Barton, 1977, pp. 145-149 